\title{
Insulin resistance and associated factors in patients with Type 1 Diabetes
}

\author{
Mônica Maria Teixeira ${ }^{*}$, Maria de Fátima Haueisen Sander Diniz ${ }^{2}$, Janice Sepúlveda Reis ${ }^{3}$, \\ Teresa Cristina Abreu Ferrari ${ }^{2}$, Maria Goretti Bravim de Castro ${ }^{4}$, Bruna Polonio Teixeira ${ }^{1}$, \\ Isabella Cristina da Silva Arantes ${ }^{1}$, Danielle Marques Bicalho ${ }^{1}$ and Rodrigo Bastos Fóscolo ${ }^{2}$
}

\begin{abstract}
Objective: To assess the presence of insulin resistance (IR) in patients with type 1 diabetes (T1DM) according to the estimated glucose disposal rate formula (eGDR) and the insulin sensitivity score (ISS) and to estimate the correlation between these two measures and identify the clinical and laboratory markers related to IR.
\end{abstract}

Research design and methods: Cross-sectional study of adults with T1DM ( $n=135)$. The results of the formulas that estimate IR were separated into quartiles and correlated with demographic data, clinical characteristics and laboratory parameters. We analyzed the total and regional adiposity by dual-energy $\mathrm{X}$-ray absorptiometry and skin fold thickness measurements.

Results: Two thirds of the patients were overweight or obese. A moderate correlation was found between eGDR and ISS $(r=0.612)$. The results of both formulas were positively correlated with BMI $(r=-0.373$ eGDR and $r=-0.721$ ISS), thoracic-abdominal fat ( $r=-0.484$ eGDR and $r=-0.758$ ISS), waist/height ratio $(r=-0.537$ eGDR and $r=-0.779$ ISS), subscapular skinfold $(\mathrm{mm})(r=-0.356 \mathrm{eGDR}$ and $r=-0.569$ ISS), total dose insulin IU/lean mass $(\mathrm{kg})(r=-0.279$ eGDR and $r=-0.398$ ISS), age (years) ( $r=-0.495$ eGDR and $r=-0.190$ ISS) and diabetes duration (years) $(r=-0.428$ eGDR and $r=-0.187$ ISS).

A moderate agreement (Kappa 0.226) was observed between the 1st quartile of results determined by the formulas in $10.4 \%$ of the patients, but the 4th quartile presented a strong correlation (Kappa 0.679). The individuals with IR that were classified in the 1st quartile by the ISS formula had a higher chance of presenting with acanthosis nigricans $(\mathrm{OR}=5.58,95 \% \mathrm{Cl}=1.46-21.3)$.

Conclusions: The correlations found in this study indicate the possibility of using clinical and laboratory data to estimate IR in patients with TDM1. The detection of IR in T1DM patients may allow early intervention and possibly impact on future diabetes complications.

Keywords: Type 1 diabetes, Insulin resistance, Estimated glucose disposal rate formula, Insulin sensitivity score

\section{Introduction}

Currently, an extensive amount of literature that explores insulin resistance (IR) and adiposity in populations of non-diabetic and type 2 diabetic patients suggests that regional adiposity may be an important determining factor of IR [1-6]. Few investigations have explored these associations in type 1 diabetes mellitus (T1DM). IR is traditionally related to type 2 diabetes

\footnotetext{
* Correspondence: monicamariateixeira@gmail.com

${ }^{1}$ Federal University of Minas Gerais UFMG, Rua Padre Rolim 769, sala 802.

Bairro São Lucas, Belo Horizonte, Minas Gerais, Brazil

Full list of author information is available at the end of the article
}

(T2DM), but its association with T1DM is also well documented [7-11]. The most probable cause for the lack of studies in this area is the difficulty of directly evaluating IR in this population. In individuals at risk for T1DM, increased IR concomitant to the decrease in beta-cell mass can alter the balance between insulin sensitivity (IS) and secretion which then precipitates hyperglycemia [12]. Thus, this imbalance could result in a more aggressive form of the autoimmune disorder, mediated by immunoinflammatory factors common to both processes, that mediates both IR and the destruction of beta cells, such as TNF- $\alpha$ and IL-6 [13]. These concepts are part of 
the "Accelerating Hypothesis" [14]. A family history of T2DM and chronic hyperglycemia (glucotoxicity) during the clinical phase of T1DM are associated with decreased peripheral glucose uptake. Other factors may also influence IS, such as age, lean body mass, ethnicity, body fat, weight, physical activity, and drug use [6,8,15-17]. In patients with T1DM, the development of coronary artery disease (CAD) occurs decades earlier and with a frequency tenfold higher than in non-diabetic individuals. Although the factors associated with increased risk of CAD in this population are well documented, its pathogenesis remains unclear [18]. IR is related to diabetic nephropathy and CAD [19], and the latter represents one of the major causes of mortality in adult the population with longlasting T1DM $[7,20,21]$. IR is an independent risk factor for the development of micro and macrovascular diseases in both T2DM and T1DM patients [7,21].

The hyperinsulinemic-euglycemic clamp technique is the gold standard for the diagnosis of IR [22]. However, the difficulty in performing, high cost of and invasive nature of this procedure limit its large scale use $[7,8]$. Some clinicians have proposed indirect and simplified approaches to estimate IR using clinical parameters of the disease and individual characteristics of the patients via mathematical formulas [23-26]. In this context, two formulas that estimate IR have been validated by comparison with the hyperinsulinemic-euglycemic clamp technique and have been used, in spite of some limitations. The first formula associates the estimated glucose disposal rate (eGDR) with the waist/hip $(\mathrm{cm})$ ratio, history of systemic arterial hypertension and the haemoglobin A1c (\%) level, which are inversely related to IR [23]. The second formula evaluates the insulin sensitivity score (ISS) based on the waist size $(\mathrm{cm})$, level of glycated haemoglobin (A1c) (\%) and triglycerides (mg/dl) [26].

Therefore, the present study aims to assess the presence of IR in patients with DM1 with the eGDR and ISS formulas, estimate the agreement between these formulas, and assess the correlation between clinical and laboratory parameters with IR. This is the first investigation of IR evaluation in a group of Brazilian type 1 diabetic patients using two mathematical formulas and adiposity markers.

\section{Subjects and methods}

This cross-sectional study was performed between January 2011 and June 2012 in Belo Horizonte, Minas Gerais, Brazil. The study included 135 patients with T1DM selected consecutively and followed up at the outpatient care department for diabetic patients at the Endocrinology Service of the Hospital Santa Casa and Hospital das Clínicas of the Universidade Federal de Minas Gerais. T1DM was diagnosed according to the criteria of the American Diabetes Association [27]: onset of the disease before 30 years of age and permanent insulinization beginning less than one year after the diagnosis [21]. Patients with A1c values greater than $11.1 \%$ (which were the maximum values used in the two formulas), a pubertal stage less of than 5, the presence of chronic renal failure, infection or pregnancy at the time of data collection were not included in the study. All subjects agreed to participate in the study and signed an informed consent form. The project was approved by the Research Ethics Committees of the institutions involved (Projects CAAE -06121203003-11 and CEP 012/2011).

The anamnesis and physical examinations of the participants were conducted by trained examiners. The following information was obtained from the clinical history: age, gender, duration of T1DM (years), total insulin dose IU/ lean mass $(\mathrm{kg})$, arterial hypertension, physical activity (present in those who performed aerobic activity or resistance for more than 180 minutes per week) and a family history of T2DM. The body weight was measured while patients wore light clothes and no shoes on scales with an accuracy of $100 \mathrm{~g}$. The height was measured with the patient barefoot, standing with feet and heels parallel, and the trunk, shoulders and head touching the stadiometer (accuracy of $0.5 \mathrm{~cm}$ ). Waist and hip circumferences were measured in centimeters at the lowest curvature between the ribs and the iliac crest and at the area of greatest gluteal protuberance, respectively. The measurement of the systolic and diastolic blood pressure (SBP and DBP, mmHg) was performed in supine and standing positions. Individuals using antihypertensive medications and/or those with a SBP $\geq 130 \mathrm{mmHg}$ and/ or DBP $\geq 80 \mathrm{mmHg}$ were considered hypertensive. The presence of acanthosis nigricans was recorded during the physical examination.

Skin fold (SF) thickness was measured at the triceps, suprailiac and subscapular areas, chest, armpit, abdomen, and thigh. The following parameters were calculated: body mass index (BMI) given by weight $(\mathrm{kg}) /$ height $^{2}(\mathrm{~m})$, waist/ height ratio $(\mathrm{cm})$, waist-hip ratio $(\mathrm{W} / \mathrm{H})$, and fat percentage (FP). We used two methods to assess body composition. The first was a dual-energy X-ray absorptiometry (DEXA; DEXA Lunar Expert, model 1081) method. Total body fat mass $(\mathrm{kg})$, free lean bone mass $(\mathrm{kg})$, and percentage of body lean mass were calculated by measuring regional arm lean mass $(\mathrm{kg})$, leg lean mass $(\mathrm{kg})$, and trunk lean mass $(\mathrm{kg})$. The separation between the trunk and legs and arms was made according to the protocol used by Shay et al. [23]. One participant was excluded from the analysis due to a lower limb amputation. From the total of 135 patients, 64 (47.4\%) were submitted to DEXA. In the second method, we measured the SF thickness three times and used the arithmetic mean of these values. The adipometer (Lange, Cambridge Scientific Industries, USA) used has an accuracy of $0.2 \mathrm{~mm}$. To calculate the SF thickness, we used Jackson and Pollock's formulas [28,29]. For 
men, SF $=1.10938-0.0008267$ (thoracic + abdominal + thigh) +0.0000016 (thoracic + abdominal + thigh ${ }^{2}-$ 0.0002574 ; and $\mathrm{FP}=[(4.95 / \mathrm{DC})-4.50] \times 100$ [28]. For women SF $=1.0994921-0.0009929$ (triceps + suprailiac + thigh) +0.0000023 (triceps + supra-iliac + thigh $)^{2}-$ 0.0001392; and $\mathrm{FP}=(5.01 / \mathrm{D} 4.57) \times 100$ [29].

Blood collections were performed after fasting for a minimum of 10 hours and abstention from alcoholic beverages for at least 72 hours. Laboratory tests consisted of the following: fasting plasma glycaemia (FPG), total cholesterol, HDL cholesterol (HDL), LDL cholesterol (LDL), triglycerides (enzymatic s3colorimetric method), A1c (determined by immunoturbidimetry and high performance liquid chromatography (HPLC), both standardized by the National Glycohemoglobin Standardization Program (NGSP)), glutamic acid decarboxylase (GAD) antibodies test, and an insulinoma-associated (IA2) antibodies test (performed by radioimmunoassay and $\mathrm{C}$ peptide by the chemiluminescence method).

IR was determined using two formulas that were validated by the hyperinsulinemic-euglycemic clamp technique. The first formula, eGDR, allows estimates of the glucose release rate [23] and is calculated based on clinical and laboratory parameters according to the following equation: $\mathrm{eGDR}=24.4-(12.97 \times \mathrm{W} / \mathrm{H})-(3.39 \times \mathrm{AH})-(0.60 \times \mathrm{A} 1 \mathrm{c})$; where $\mathrm{W} / \mathrm{H}$ is the value of the waist/hip ratio and $\mathrm{AH}$ indicates the presence of arterial hypertension (yes $=1$, no $=0$ ). The second formula estimates the ISS [26] and is calculated with the equation: LogeIS $=4.64725-0.02032(\mathrm{~W}, \mathrm{~cm})$ 0.0977 (A1c, \%) - 0.00235 (TG, mg/dl); where Loge IS is the logarithm of IS, W is the waist size, and TG is the triglyceride level.

The results of the eGDR and ISS formulas were separated into quartiles as follows: eGDR 1st quartile ( $\leq 6.61)$, 2nd quartile (6.62 to 8.76$)$, 3rd quartile (8.77 to $10.33)$, and 4th quartile ( $>10.33)$; and ISS 1st quartile $(\leq 6.22)$, 2nd quartile (6.23 to 8.16$)$, 3rd quartile (8.17 to $9.56)$, and 4th quartile (>9.56).

Sample size was calculated according to the following parameters: 0.25 prevalence of metabolic syndrome (and hence, IR) in T1DM patients [10,30], 0.12 estimation error, $5 \%$ alpha and $20 \%$ power. The estimated sample size was 120 patients for an error tolerance of 0.05 . These patients were randomly selected by simple randomization from a pool of $350 \mathrm{DM} 1$ patients that attended the institutions where the research was performed.

Statistical analyses were performed using the computer software IBM SPSS, version 20.0 (SPSS Inc., Chicago, IL, USA) and R version 3.01 (2013-05-16, Vienna, Austria). We used histograms and Shapiro-Wilk tests to verify the normality of continuous data. The Student's T tests and Mann-Whitney $U$ tests were used to compare means and medians of continuous variables, and the Person's chi-square test or Fisher's exact test to compare categorical variables between the men and women. Spearman's correlation coefficient was used to evaluate the correlation between the IR formulas and markers of adiposity, clinical findings, laboratory parameters and T2DM family history. The original data from the formulas was calculated and divided into quartiles because the formulas do not have cutoff values for comparative analyses. We divided patients into three groups (1st quartile, 2nd + 3rd quartiles and 4th quartile). The Jonckheere-Terpstra test was used to compare medians of continuous variables (without Gaussian normal distribution) between the three groups (1st quartile, 2nd +3 rd quartiles and 4th quartile) and Chi-square test for trends and Fisher's exact test to compare categorical variables between the three groups (1st quartile, 2nd + 3rd quartiles and 4th quartile). All analyses were performed using $\mathrm{p}<0.05$ as a statistically significant level. The two formulas in question were compared using the Kappa coefficient. Finally, the association between the 1st quartile of the ISS formula data and the occurrence acanthosis nigricans was analyzed using the odds ratio.

\section{Results}

The characteristics of the 135 subjects with T1DM are presented in Table 1, which shows the clinical and laboratory profiles according to gender. The proportion of smokers was higher among men $(20.4 \%$ vs. $8.2 \% \mathrm{p}=$ 0.029 ). A total of $46.6 \%$ of men and $33.8 \%$ of women were classified as overweight (BMI $\left.\geq 25 \mathrm{~kg} / \mathrm{m}^{2}\right)$. In the study population, $71.5 \%$ of patients had a positive family history of T2DM. The auto antibodies anti-GAD and anti-IA2 were positive in $87.3 \%$ and $25 \%$ of women and $92.1 \%$ and $16.7 \%$ of men, respectively. C-peptide levels were undetectable in $88.1 \%$ of women and $88.9 \%$ of men.

Table 2 shows the correlation analysis between the ISS and eGDR formulas by gender and fat markers, clinical and laboratory parameters, T2DM family history and physical activity. According to the Spearman's rank correlation coefficient, a moderate positive correlation was found between the values of the two formulas $(r=0.612$, $\mathrm{p}<0.001$ ) (Figure 1).

The clinical and laboratory characteristics of diabetic patients belonging to the 1 st and 4th quartiles according to the eGDR and ISS formulas are presented in detail in Tables 3 and 4 . The variables that were significantly different between the 1st quartile and 4th quartile of the eGDR formula data comprise age, duration of diabetes, BMI, thoracic-abdominal fat (absolute and percentage), total dose insulin IU/lean mass $(\mathrm{kg})$, arm fat, waist/ height ratio and scapular skinfold. The variables that were significantly different between the 1st quartile and 4th quartile of the ISS formula data comprise age, duration of diabetes, BMI, total insulin dose per lean mass, total fat percentage, arm fat, leg fat, thoracoabdominal fat (absolute and percentage), scapular skinfold, triceps 
Table 1 Clinical and laboratory profile of type 1 diabetic patients

\begin{tabular}{|c|c|c|c|}
\hline Variables & Male & Female & $P$ value \\
\hline$N=135$ & $58(43 \%)$ & 77 (57\%) & \\
\hline Age (years) & $30(17-68)$ & $27(12-58)$ & 0.139 \\
\hline TDM1 duration (years) & $15.5(1-48)$ & $15.0(1-49)$ & 0.556 \\
\hline eGDR & $8.49(1.26-11.82)$ & $9.3(2.35-12.6)$ & 0.055 \\
\hline ISS & $7.60( \pm 2.34)$ & $8.30( \pm 2.28)$ & 0.090 \\
\hline $\mathrm{BMI}^{\dagger}\left(\mathrm{kg} / \mathrm{m}^{2}\right)$ & $24.0(19.0-36.0)$ & $24.0(17.0-46.0)$ & 0.255 \\
\hline Waist (cm) & $84.5(65-119)$ & $78.0(64-123)$ & 0.001 \\
\hline Hips (cm) & $98.0(80-120)$ & $96.0(90-150)$ & 0.938 \\
\hline Waist/height ratio & 49.3(36.1-70.4) & $48.1(38.5-78.9)$ & 0.81 \\
\hline Waist/hip ratio & $0.85(0.75-1.12)$ & $0.79(0.67-1.48)$ & $<0.001$ \\
\hline Total insulin dose UI/Lean mass $(\mathrm{kg})^{\ddagger}$ & $0.98(0.32-3.15)$ & $1.14(0.19-3.35)$ & 0.085 \\
\hline Total lean mass $(\mathrm{kg})^{\ddagger}$ & $53.15( \pm 9.55)$ & $36.82(41.63)$ & $<0.001$ \\
\hline Thoracic-abdominal fat $(\mathrm{kg})^{\ddagger}$ & $3.63(1.0-28.65)$ & $6.65(2.34-17.37)$ & 0.053 \\
\hline Leg fat $(\mathrm{kg})^{\ddagger}$ & $3.86(0.85-12.93)$ & $6.81(2.3-16.34)$ & $<0.001$ \\
\hline Arm fat $(\mathrm{kg})^{\ddagger}$ & $0.738(0.182-3.743)$ & $1.81(0.51-6.78)$ & $<0.001$ \\
\hline Total lean mass percent ${ }^{\ddagger}$ & $83.8(56-95)$ & $68.7(50-86)$ & $<0.001$ \\
\hline Total Fat Percent $^{\ddagger}$ & $16.24(5.3-43.6)$ & $33.00(14.4-50)$ & $<0.001$ \\
\hline Thoracic-abdominal total percent $^{\ddagger}$ & $14.76(5-68.4)$ & $26.30(11-50.3)$ & 0.004 \\
\hline Leg fat percent ${ }^{\ddagger}$ & $18.90(8.7)$ & $39.27(8.33)$ & $<0.001$ \\
\hline Arm fat percent ${ }^{\ddagger}$ & $11.1(4.1-32.6)$ & $38.0(14.9-59.1)$ & $<0.001$ \\
\hline Triceps skinfold (mm) & $12.30(4.33-31.67)$ & $20.67(8.33-48.67)$ & $<0.001$ \\
\hline Scapular skinfold (mm) & $15.70(6.33-41.67)$ & $18.33(6.33-39.0)$ & 0.035 \\
\hline Total cholesterol (mg/dL) & $160(76-282)$ & $169(85-332)$ & 0.043 \\
\hline HDL cholesterol (mg/dL) & $50(27-81)$ & $58(36-124)$ & 0.001 \\
\hline LDL cholesterol (mg/dL) & $94.0(35-178)$ & $98.0(20-252)$ & 0.419 \\
\hline Triglycerides (mg/dL) & $62.5(26-310)$ & $63(25-295)$ & 0.697 \\
\hline Systolic arterial pressure $\mathrm{mmHg}$ & $120(90-200)$ & $120(90-160)$ & 0.012 \\
\hline Diastolic arterial pressure $\mathrm{mmHg}$ & $80(50-120)$ & $80(50-100)$ & 0.017 \\
\hline A1c (\%) & $7.6(5.4-11)$ & $7.9(5.8-11.1)$ & 0.328 \\
\hline $\mathrm{HbA1c}(\mathrm{mmol} / \mathrm{mol})$ & $60(36-94)$ & $63(40-98)$ & 0.328 \\
\hline Total insulin dose (IU/kg) & $55(12-340)$ & $44(8-122)$ & 0.036 \\
\hline Physical activity - yes & $41(70.7 \%)$ & $43(56.6 \%)$ & 0.107 \\
\hline Acanthosis - yes* & $4(7.3 \%)$ & $6(8.2 \%)$ & 0.10 \\
\hline Family history of TDM2 - yes & $40(70.2 \%)$ & $53(72.6 \%)$ & 0.845 \\
\hline
\end{tabular}

P value: Person's chi- square, Fisher's exact test*, Student's $T$ test, and the Mann-Whitney test for differences between, frequencies, frequencies, means and medians. ${ }^{\dagger}$ Body mass index $=$ weight $(\mathrm{kg}) /$ height $(\mathrm{m})^{2}$.

${ }^{\ddagger}$ Patients who underwent densitometry for analysis of body composition $(n=64)$.

eGDR estimated glucose disposal rate, ISS insulin sensitivity score, BMI body mass index, A1c glycated haemoglobin.

skinfold, total lean mass (absolute and percentage), percentage of total fat, and hip and waist/height ratio. A moderate positive association was found between the first and 4th ISS quartiles regarding HDL values and the presence of acanthosis nigricans.

The variables that were strongly concurrent between the 1st and 4th quartiles for both formulas comprise BMI, waist/height ratio, subscapular skinfold, total dose insulin IU/lean mass $(\mathrm{kg})$, age, diabetes duration and thoracoabdominal fat (absolute and percentage).

In the studied population, $14(10.4 \%)$ patients presented results calculated by both formulas that corresponded with the 1st quartile, suggesting IR, and 63 $(85.7 \%)$ patients were overweight or obese. The agreement between the 1st quartiles of the eGDR and ISS formulas was slight-to-moderate $($ Kappa $=0.226)$, and the 
Table 2 Spearman linear correlation between eGDR, ISS and clinical and laboratory profiles by gender

\begin{tabular}{|c|c|c|c|c|}
\hline \multirow[t]{3}{*}{ Variables } & \multicolumn{2}{|c|}{ eGDR } & \multicolumn{2}{|c|}{ ISS } \\
\hline & \multicolumn{2}{|c|}{ SLC General } & \multicolumn{2}{|c|}{ SLC General } \\
\hline & SLC Male & SLC Female & SLC Male & SLC Female \\
\hline \multirow[t]{2}{*}{ Total lean mass $(\mathrm{kg})^{\S}$} & \multicolumn{2}{|c|}{$-0.121(0.335)$} & \multicolumn{2}{|c|}{$-0.262(0.034)$} \\
\hline & $0.064(0.751)$ & $-0.103(0.533)$ & $-0.443(0.021)$ & $-0.262(0.107)$ \\
\hline \multirow[t]{2}{*}{ Thoracoabdominal fat $(\mathrm{kg})^{\S}$} & \multicolumn{2}{|c|}{$-0.484(<0.001)$} & \multicolumn{2}{|c|}{$-0.758(<0.001)$} \\
\hline & $-0.560(0.002)$ & $-0.478(0.003)$ & $-0.825(<0.001)$ & $-0.743(<0.001)$ \\
\hline \multirow[t]{2}{*}{ Leg fat $(\mathrm{kg})^{\S}$} & \multicolumn{2}{|c|}{$-0.068(0.592)$} & \multicolumn{2}{|c|}{$-0.351(0.004)$} \\
\hline & $-0.296(0.134)$ & $-0.078(0.648)$ & $-0.563(0.002)$ & $-0.374(0.23)$ \\
\hline \multirow[t]{2}{*}{ Arm fat $(\mathrm{kg})^{\S}$} & \multicolumn{2}{|c|}{$-0.381(0.002)$} & \multicolumn{2}{|c|}{$-0.592(<0.001)$} \\
\hline & $-0.497(0.08)$ & $-0.390(0.17)$ & $-0.667(0.001)$ & $-0.662(<0.001)$ \\
\hline \multirow[t]{2}{*}{ Percentage of total lean mass ${ }^{\S}$} & \multicolumn{2}{|c|}{$0.262(0.036)$} & \multicolumn{2}{|c|}{$0.436(<0.001)$} \\
\hline & $0.464(0.015)$ & $0.322(0.052)$ & $0.659(0.001)$ & $0.534(<0.001)$ \\
\hline \multirow[t]{2}{*}{ Percent total $\mathrm{Fat}^{\S}$} & \multicolumn{2}{|c|}{$-0.268(0.032)$} & \multicolumn{2}{|c|}{$-0.476(<0.001)$} \\
\hline & $-0.464(0.015)$ & $-0.349(0.034)$ & $-0.659(0.001)$ & $-0.640(<0.001)$ \\
\hline \multirow[t]{2}{*}{ Percentage of thoracoabdominal $\mathrm{fat}^{\S}$} & \multicolumn{2}{|c|}{$-0.359(0.004)$} & \multicolumn{2}{|c|}{$-0.574(<0.001)$} \\
\hline & $-0.369(0.058)$ & $-0.464(0.004)$ & $-0.592(0.001)$ & $-0.731(<0.001)$ \\
\hline \multirow[t]{2}{*}{ Percent fat leg ${ }^{\S}$} & \multicolumn{2}{|c|}{$-0.024(0.848)$} & & \\
\hline & $-0.311(0.114)$ & $-0.067(0.695)$ & $-0.487(0.01)$ & $-0.260(0.120)$ \\
\hline Percent arm fat ${ }^{\S}$ & & & & \\
\hline & $-0.545(0.003)$ & $-0.326(0.049)$ & $-0.718(<0.001)$ & $-0.619(<0.001)$ \\
\hline Triceps skinfold (mm) & & & & \\
\hline & $-0.286(0.44)$ & $-0.906(0.457)$ & $-0.595(<0.001)$ & $-0.380(0.002)$ \\
\hline Subscapular skinfold (mm) & & & & \\
\hline & $-0.485(0.001)$ & $-0.374(0.003)$ & $-0.676(<0.001)$ & $-0.594(<0.001)$ \\
\hline HDL cholesterol (mg/dL) & & & & \\
\hline & $0.076(0.570)$ & $0.079(0.496)$ & $0.197(0.138)$ & $0.185(0.108)$ \\
\hline Total cholesterol (mg/dL) & & & & \\
\hline & $0.152(0.259)$ & $-0.022(0.846)$ & $-0.205(0.125)$ & $-0.147(0.201)$ \\
\hline $\mathrm{BMI}^{\| \dagger}\left(\mathrm{kg} / \mathrm{m}^{2}\right)$ & & & & \\
\hline Waist/height ratiol & & & & \\
\hline Age (years) $\|^{\|}$ & & & & \\
\hline Diabetes duration (years) $)^{\|}$ & & & & \\
\hline Total dose insulin IU/Lean mass $(\mathrm{kg})^{\S \|}$ & & & & \\
\hline Acanthosis nigricans - yes" & & & & \\
\hline LDL cholesterol $(\mathrm{mg} / \mathrm{dL})^{\|}$ & & & & \\
\hline Family history of TDM $2^{\|}$- yes & & & & \\
\hline Physical activity - yes" & & & & \\
\hline
\end{tabular}

$P$ value: Spearman correlation.

${ }^{\dagger}$ Body mass index = weight $(\mathrm{kg}) /$ height $(\mathrm{m})^{2}$.

${ }^{\S}$ Patients who underwent bone densitometry for body composition analysis $(n=64)$.

"Variables where there was no significant difference for the gender factor. See Table 1.

agreement among the four quartiles of the two formulas was strong $($ Kappa $=0.679)$. The individuals with IR classified in the 1st quartile by the ISS formula had a higher chance of presenting with acanthosis nigricans $(\mathrm{OR}=5.58,95 \% \mathrm{CI}=1.46-21.3)$.

\section{Discussion}

According to the classic definition of T1DM, individuals with a total deficiency of insulin are characterized as T1DM patients. During the last two decades there has been an increase in the overweight population of type 1 


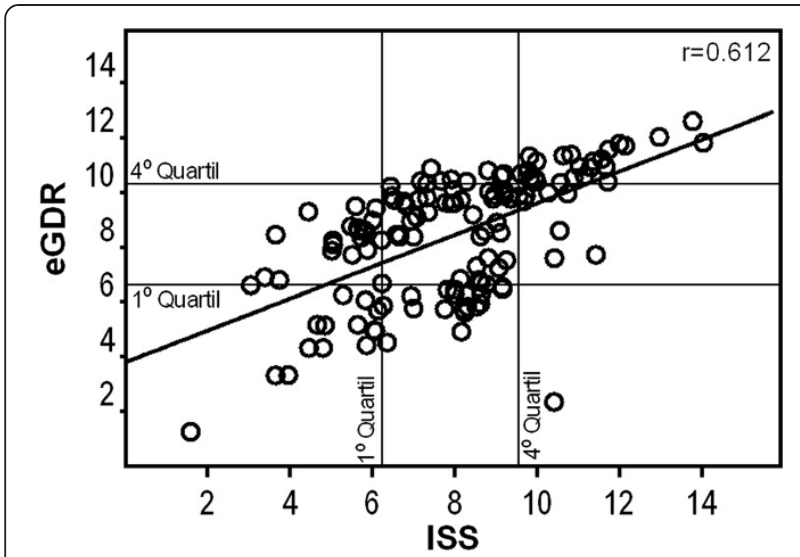

Figure 1 Scatter plot of the correlation values between the first quartile and fourth quartile of data from the formulas that estimate the glucose disposal rate (eGDR) and the insulin sensitivity score (ISS) and the Spearman correlation coefficient. diabetic patients, and the prevalence of overweight patients has tripled from the 1980s to the 1990s [31], following the trend of the general population [16]. In our study population, $46.6 \%$ of men and $33.8 \%$ of women were classified as overweight (BMI $\geq 25 \mathrm{~kg} / \mathrm{m}^{2}$ ). Among the patients who underwent DEXA, we found an increased percentage of total body fat in both men and women, specifically in the groups classified into the 1st quartile by the formulas. In this group, the percentage of total and thoracoabdominal fat, subscapular skinfold (SF), and the waist/height ratio, which are markers of visceral fat, were increased significantly compared to the other quartiles of both formulas. Forty-four percent of young Hispanic Americans with T1DM from the SEARCH study were overweight or obese [32], suggesting a new phenotype in a group of patients that were considered lean until that time. These results also confirmed previous observations in T1DM patients showing that fat stored in the abdomen is associated with an

Table 3 Clinical and laboratory characteristics of type 1 diabetic patients compared by eGDR quartiles

\begin{tabular}{|c|c|c|c|c|}
\hline Variables & eGDR $1^{\text {st }}$ quartile & eGDR $2^{\text {nd }}$ and $3^{\text {rd }}$ quartiles & eGDR $4^{\text {th }}$ quartile & $P$ value \\
\hline Patients & $n=33(24.4 \%)$ & $n=69(51.1 \%)$ & $n=33(24.4 \%)$ & \\
\hline Gender (Male) & $18(54.5 \%)$ & $29(42.0 \%)$ & $11(33.3 \%)$ & 0.083 \\
\hline Age (years) & $37(20-68)$ & $29(12-58)$ & $23(12-55)$ & $<0.001$ \\
\hline Duration of diabetes (years) & $21(2-48)$ & $14(1-49)$ & $10(0-27)$ & $<0.001$ \\
\hline $\mathrm{BMI}^{\dagger}\left(\mathrm{kg} / \mathrm{m}^{2}\right)$ & $25(19-35)$ & $24(17-46)$ & $21(18-28)$ & 0.001 \\
\hline Waist/height ratio & $52.6(40.5-70.4)$ & $50(38.7-78.8)$ & $44.2(36.1-52.2)$ & $<0.001$ \\
\hline Total insulin dose IU/Lean mass $(\mathrm{kg})^{\S}$ & $1.13(0.46-3.15)$ & $1.14(0.52-3.35)$ & $0.91(0.19-1.63)$ & 0.059 \\
\hline Total lean mass $(\mathrm{kg})^{\S}$ & $40(32.9-64.2)$ & $41(30.1-81.1)$ & $38.5(30.1-58.0)$ & 0.656 \\
\hline Thoracoabdominal fat $(\mathrm{kg})^{\S}$ & $9.38(2.3-28.7)$ & $6.34(1.0-20.1)$ & $4.71(1.7-12.5)$ & 0.002 \\
\hline Leg fat $(\mathrm{kg})^{\S}$ & $5.40(0.9-11.0)$ & $6.29(0.9-12.9)$ & $5.89(1.8-16.3)$ & 0.901 \\
\hline $\operatorname{Arm}$ fat $(\mathrm{kg})^{\S}$ & $1.98(0.3-6.8)$ & $1.46(0.2-3.7)$ & $1.03(0.3-4.8)$ & 0.017 \\
\hline Total lean mass percentage ${ }^{\S}$ & $0.70(0.5-0.9)$ & $0.72(0.6-1.0)$ & $0.78(0.5-0.9)$ & 0.108 \\
\hline Total fat percentage $\mathrm{e}^{\S}$ & $0.29(0.07-0.5)$ & $0.28(0.05-0.40)$ & $0.21(0.08-0.49)$ & 0.103 \\
\hline Thoracoabdominal fat percentage ${ }^{\S}$ & $0.29(0.09-0.54)$ & $0.25(0.05-0.41)$ & $0.19(0.08-0.68)$ & 0.02 \\
\hline Leg fat percentage $e^{\S}$ & $0.31(0.06-0.50)$ & $0.31(0.06-0.48)$ & $0.30(0.11-0.60)$ & 0.852 \\
\hline Arm fat percentage $\mathrm{e}^{\S}$ & $0.32(0.55-0.59)$ & $0.30(0.4-0.43)$ & $0.26(0.45-0.56)$ & 0.122 \\
\hline Triceps skinfold (mm) & $15.5(6.6-30.0)$ & $17.8(4.3-48.7)$ & $19.0(5.3-28.7)$ & 0.730 \\
\hline Scapular skinfold (mm) & $19.5(7.7-39.0)$ & $17.3(6.3-41.7)$ & $13.8(6.3-26.0)$ & 0.001 \\
\hline Acanthosis (yes)* & $2(6.5 \%)$ & $7(10.8 \%)$ & $1(3.1 \%)$ & 0.432 \\
\hline Physical activity (yes) & $17(53.1 \%)$ & $43(62.3 \%)$ & $24(72.7 \%)$ & 0.103 \\
\hline Family history of DM2 (yes) & $24(72.7 \%)$ & $43(66.2 \%)$ & $26(81.3 \%)$ & 0.457 \\
\hline Total insulin dose (IU/day) & $48(20-340)$ & $52.5(17-161)$ & $36(8-85)$ & 0.041 \\
\hline Total Cholesterol (mg/dl) & $166(104-322)$ & $166(85-240)$ & $165(76-250)$ & 0.853 \\
\hline $\mathrm{HDL}(\mathrm{mg} / \mathrm{dl})$ & $56(27-87)$ & $52(32-124)$ & $58(32-107)$ & 0.474 \\
\hline $\mathrm{LDL}(\mathrm{mg} / \mathrm{dl})$ & $100(57-252)$ & $96(20-178)$ & $93(35-150)$ & 0.357 \\
\hline
\end{tabular}

P-value: Jonckheere-Terpstra test, Chi-square for trends, Fisher Exact Test* for comparisons of medians, frequencies and frequencies.

${ }^{\dagger}$ Body mass index $=$ weight $(\mathrm{kg}) /$ height $(\mathrm{m})^{2}$.

${ }^{\S}$ Patients who underwent densitometry for the analysis of body composition $(n=64)$. 
Table 4 Clinical and laboratory characteristics of type 1 diabetic patients compared by ISS quartiles

\begin{tabular}{|c|c|c|c|c|}
\hline Variables & ISS $1^{\text {st }}$ quartile & ISS $2^{\text {nd }}$ and $3^{\text {rd }}$ quartiles & ISS4 ${ }^{\text {th }}$ quartile & $P$ value \\
\hline Patients & $n=34(25.2 \%)$ & $n=68(50.4 \%)$ & $\mathrm{n}=33(24.4 \%)$ & \\
\hline Gender (Male) & $18(52.9 \%)$ & $30(44.1 \%)$ & $10(30.3 \%)$ & 0.063 \\
\hline Age (years) & $32(15-68)$ & $27(12-62)$ & $25(15-55)$ & 0.016 \\
\hline Duration of diabetes (years) & $17(1-49)$ & $16(2-43)$ & $10(0-27)$ & 0.020 \\
\hline BMI $\left(\mathrm{kg} / \mathrm{m}^{2}\right)^{\dagger}$ & $27.5(19-46)$ & $24(17-30)$ & $21(18-26)$ & $<0.001$ \\
\hline Waist/height ratio $(\mathrm{cm})$ & $56.8(40.5-78.8)$ & $49.0(38.7-61.9)$ & $43.7(36.1-51.7)$ & $<0.001$ \\
\hline Total insulin dose IU/Lean Mass $(\mathrm{kg})^{\S}$ & $1.43(0.53-3.35)$ & $1.05(0.46-1.77)$ & $0.92(0.19-1.63)$ & 0.002 \\
\hline Total lean mass $(\mathrm{kg})^{\S}$ & $0.63(0.5-0.9)$ & $0.74(0.5-1.0)$ & $0.79(0.7-0.9)$ & 0.001 \\
\hline Thoracoabdominal fat $(\mathrm{kg})^{\S}$ & $13.13(7.2-28.7)$ & $6.28(1.0-13.6)$ & $3.4(1.5-6.9)$ & $<0.001$ \\
\hline Leg fat $(\mathrm{kg})^{\S}$ & $7.10(3.6-12.9)$ & $5.45(0.9-16.3)$ & $4.76(1.8-10.4)$ & 0.011 \\
\hline Arm fat $(\mathrm{kg})^{\S}$ & $2.65(1.2-6.8)$ & $1.36(0.2-4.9)$ & $0.816(0.2-2.2)$ & 0.001 \\
\hline Total lean mass percentage ${ }^{\S}$ & $0.63(0.5-0.9)$ & $0.74(0.5-1.0)$ & $0.79(0.7-0.9)$ & 0.001 \\
\hline Total fat percentage $\mathrm{e}^{\S}$ & $0.37(0.18-0.50)$ & $0.25(0.05-0.49)$ & $0.20(0.08-0.34)$ & $<0.001$ \\
\hline Thoracoabdominal fat percentage ${ }^{\S}$ & $0.33(0.22-0.50)$ & $0.21(0.05-0.41)$ & $0.16(0.06-0.68)$ & $<0.001$ \\
\hline Leg fat percentage $e^{\S}$ & $0.35(0.14-0.48)$ & $0.33(0.06-0.60)$ & $0.29(0.11-0.49)$ & 0.237 \\
\hline Arm fat percentage $\mathrm{s}^{\S}$ & $0.39(0.16-0.59)$ & $0.28(0.04-0.56)$ & $0.18(0.04-0.41)$ & 0.001 \\
\hline Triceps skinfold (mm) & $21.7(9.7-26.6)$ & $15.7(4.3-30.0)$ & $15.0(5.3-25.7)$ & 0.003 \\
\hline Scapular skinfold (mm) & $24.3(14.7-41.7)$ & $16.0(6.3-36.0)$ & $12.0(6.3-23.7)$ & $<0.001$ \\
\hline Acanthosis (yes)* & $6(19.4 \%)$ & $3(4.6 \%)$ & $1(3.1 \%)$ & 0.013 \\
\hline Physical activity (yes) & $19(57.6 \%)$ & $43(63.2 \%)$ & $22(66.7 \%)$ & 0.447 \\
\hline Family history of DM2 (yes) & $25(78.1 \%)$ & $44(66.7 \%)$ & $24(75 \%)$ & 0.783 \\
\hline Total insulin dose (IU/day) & $60(34-340)$ & $46(17-111)$ & $36(8-85)$ & $<0.001$ \\
\hline Total cholesterol (mg/dL) & $169(117-282)$ & $167(76-332)$ & $162(76-250)$ & 0.268 \\
\hline $\mathrm{HDL}(\mathrm{mg} / \mathrm{dL})$ & $46(27-87)$ & $57(35-107)$ & $56(32-124)$ & 0.004 \\
\hline LDL (mg/dL) & $99(49-178)$ & $96(20-252)$ & $88(35-150)$ & 0.127 \\
\hline
\end{tabular}

P-value: Jonckheere-Terpstra test, Chi-square for trends, Fisher Exact Test* for comparisons of medians, frequencies and frequencies.

${ }^{\dagger}$ Body mass index = weight $(\mathrm{kg}) /$ height $(\mathrm{m})^{2}$.

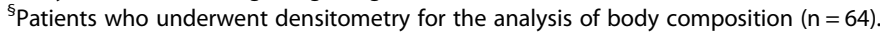

increased risk of cardiovascular disease. Our data are in agreement with the results of a study by Shay et al. [24] that showed associations between total and regional adiposity, determined by DEXA. The negative association between insulin sensitivity in T1DM and regional and overall adiposity measures improved the prediction of the eGDR and ISS equations for identifying individuals with T1DM at risk for IR. This further supports the relationship established between general obesity and IR in the studied population. The phenotypical change in the individuals with T1DM is most likely related to the augmentation of the use of insulin, irregular food habits, long time periods spent in sedentary activities, insufficient physical activities and, primarily, genetic backgrounds.

The eGDR and ISS formulas were associated with the following general clinical features: BMI, thoracoabdominal fat, subscapular SF and waist/height ratio. The results of many studies show that IR is related to waist circumference, which, despite limitations, is a useful clinical marker of abdominal adiposity. The association of the formulas with visceral fat deposits was strong in our study. Uncertainty still exists regarding the best way to measure adiposity and evaluate metabolic risks in T1DM patients. DEXA is quickly becoming the preferred technique to evaluate body fat distribution, but the high accuracy provided by this method is associated with increased operational costs. Although DEXA is clinically useful to quantify regional adiposity, current studies suggest that this method is not necessary for the estimation of IR in the general population of individuals with T1DM [24]. More useful clinical markers of obesity, such as BMI, and abdominal adiposity, such as waist and waist/height ratio, have exhibited strong associations with IR. Our results support the regular use of these simple and inexpensive measures to evaluate the risk of IR in T1DM patients.

Our results provide evidence for an association between the formulas used to determine IR and insulin 
dose per lean body mass in type 1 diabetic patients. Available evidence suggests that the insulin dose by lean mass and by body surface may be associated with IR [33]. Similar to the increased values of obesity and triglyceride markers, the presence of arterial hypertension, low HDL levels and acanthosis nigricans are related to central adiposity and IR [34]. In the group of patients analyzed using the IR formulas, in addition to the positive associations regarding the previously mentioned variables, a strong negative correlation between the amount of thoracoabdominal fat and the ISS value $(r=-0.758$ $\mathrm{p}<.001$ ) was observed, which provides further evidence that an increased amount of fat stored in the abdomen could be a risk factor for the development of IR. Furthermore, ISS was also significantly associated with acanthosis nigricans (a clinical marker of IR), triceps SF, percentage of total fat, percentage of lean mass, and HDL suggesting its enhanced usefulness in the classification of IR patients. This most likely occurs because the ISS formula includes the triglyceride level, which is an important factor associated with of IR. We found associations between age and duration of diabetes in years with IR in both formulas, but the association was stronger with the eGDR formula. A possible explanation for these associations is that hypertension, a component of the formula, is more prevalent in T1DM patients after several years of the disease, although other factors were independently associated with increased risk of hypertension in T1DM as older age, male sex, family history of hypertension, greater baseline body mass index, weight gain, and higher albumin excretion rate [35]. Reaven first drew attention to the association of insulin resistance, obesity, high plasma triglycerides and low HDL cholesterol with hypertension in the type 2 diabetes. We found the same associations for the patients classified into the first quartiles by both formulas for type 1 diabetics [36].

The following limitations of our study should be taken into account. The current design was cross-sectional and did not allow the establishment of a temporal relationship between IR, regional adiposity, and the development of diabetes complications. The percentage of patients who underwent DEXA was approximately $50 \%$ of those included in the study. This occurred due to logistical difficulties. We found no correlation between physical activity, history of T2DM and serum levels of LDL, unlike some authors who showed a correlation with family history of T2DM and serum levels of LDL [17]. However, we found an inverse correlation between IR and lean mass, an important marker of physical activity. Physical activity plays an important role in delaying disease progression and is inversely related to mortality in T1DM patients [37]. The use of a simplified questionnaire concerning physical activity may have been a source of bias. In poorly controlled diabetic patients, IR can also result from glucotoxicity because high blood glucose levels increases IR [10]. It is well known that good glycaemia control reduces weight gain and possibly decreases cardiovascular risk factors [38,39]. Our population is characterized by miscegenation. However, when our findings were compared to those of European populations, which are ethnically different, they did not differ. Findings similar to our results were found in a Polish study in which IR was evaluated by euglycaemic clamp in 202 patients with T1DM. The authors found associations between the same variables: BMI, subscapular SF, total insulin dose, total body fat, blood pressure, A1c, waist size, triglycerides and age [24]. We found no association between other regional adiposity markers and the values of the formulas; however, the evaluations in the Polish study were based only on SF thickness, and no densitometry measures were performed.

Longitudinal studies are needed to elucidate the causal relationship between increasing adiposity and the development of IR, CAD and nephropathy in populations with T1DM. The determination of the role of IR in the natural course of the disease and therapies that reduce IR, such as changes in lifestyle, weight control, the use of metformin [40] and control of oxidative stress, could avoid vascular damage in these patients [41].

In summary, our data, similar those of other studies, suggest that we can determine the presence of IR among type 1 diabetic patients by using clinical and laboratory elements because performing hyperinsulinemic-euglycemic clamp is impractical in population studies. In our analysis, data regarding total and regional body fat improved the estimation of IS. As stated by other authors, the analysis of IR risk factors is important for the overall trend of searching for a simple method that could be used in population studies and clinical practice [42].

Competing interests

The authors declare that they have no competing interests.

\section{Authors' contributions}

RBF and MMT conceived and designed the study. MMT, JSR, BPT, ICSA, and $\mathrm{DMB}$ performed the clinical investigation. MGBC performed DEXA. MMT, RBF, MFHSD and TCAF analysed the data. MMT, RBF, MFHSD, BPT and TCAF wrote/ reviewed the paper. All authors read and approved the final manuscript.

\section{Acknowledgments}

Statement of assistance: The authors give special thanks to Fernando Henrique Pereira for statistical consultation.

\section{Guarantor}

Mônica Maria Teixeira is the guarantor of this work and, as such, had full access to all of the data in the study and takes responsibility for the integrity of the data and the accuracy of the data analysis.

\section{Funding/financial support}

This research did not receive any specific grant from any funding agency in the public, commercial or not-for-profit sector. 


\section{Author details}

${ }^{1}$ Federal University of Minas Gerais UFMG, Rua Padre Rolim 769, sala 802. Bairro São Lucas, Belo Horizonte, Minas Gerais, Brazil. ²Department of Internal

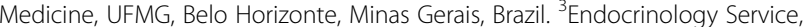
Santa Casa of Belo Horizonte, Belo Horizonte, Minas Gerais, Brazil. ${ }^{4}$ Centre for Studies in Densitometry, Belo Horizonte, Minas Gerais, Brazil.

Received: 24 August 2014 Accepted: 17 November 2014 Published: 1 December 2014

\section{References}

1. Abate N, Garg A, Peshock RM, Stray-Gundersen J, Adams-Huet B, Grundy SM: Relationship of generalized and regional adiposity to insulin sensitivity in men with NIDDM. Diabetes 1996, 45:1684-1693.

2. Rattarasarn C: Physiological and pathophysiological regulation of regional adipose tissue in the development of insulin resistance and type 2 diabetes. Acta Physiol (Oxf) 2006, 186:87-101.

3. Basat O, Ucak S, Ozkurt H, Basak M, Seber S, Altuntas Y: Visceral adipose tissue as an indicator of insulin resistance in nonobese patients with new onset type 2 diabetes mellitus. Exp Clin Endocrinol Diabetes 2006, 114:58-62.

4. Bjorntorp P: Regional fat distribution-implications for type II diabetes. Int J Obes Relat Metab Disord 1992, 16(Suppl 4):S19-S27.

5. Miyazaki Y, Glass L, Triplitt C, Wajcberg E, Mandarino L, DeFronzo RA: Abdominal fat distribution and peripheral and hepatic insulin resistance in type 2 diabetes mellitus. Am J Physiol Endocrinol Metab 2002, 283:E1135-E1143.

6. Bjorntorp P: Metabolic implications of body fat distribution. Diabetes Care 1991, 14:1132-1143.

7. Kilpatrick ES, Rigby AS, Atkin SL: Insulin resistance, the metabolic syndrome, and complication risk in type 1 diabetes: "double diabetes" in the diabetes control and complications trial. Diabetes Care 2007, 30:707-712.

8. Shay CM, Secrest AM, Goodpaster BH, Kelsey SF, Strotmeyer ES, Orchard TJ: Regional adiposity and risk for coronary artery disease in type 1 diabetes: does having greater amounts of gluteal-femoral adiposity lower the risk? Diabetes Res Clin Pract 2010, 89:288-295.

9. Xu P, Cuthbertson D, Greenbaum C, Palmer JP, Krischer JP: Role of insulin resistance in predicting progression to type 1 diabetes. Diabetes Care 2007, 30:2314-2320.

10. Dib SA: Resistência à insulina e síndrome metabólica no diabetes melito do tipo 1. Ara Bras Endocrinol Metab 2006, 50:250-263.

11. Yki-Jarvinen $H$, Koivisto VA: Natural course of insulin resistance in type 1 diabetes. New Engl J Med 1986, 315:224-230.

12. Fourlanos S, Narendran P, Byrnes GB, Colman PG, Harrinson LC: Insulin resistance is a risk factor for progression to Type 1 diabetes. Diabetologia 2004, 47:1661-1667.

13. Nokoff NJ, Rewers M, Cree Green M: The interplay of autoimmunity and Insulin resistance in type 1 diabetes. Discov Med 2012, 13:115-122.

14. Wilkin TJ: The convergence of type 1 and type 2 diabetes in childhood: the accelerator hypothesis. Pediatr Diabetes 2012, 13:334-339.

15. Perseghin G, Lattuada G, Danna M, Sereni LP, Maffi P, De Cobelli F, Battezzati A, Secchi A, Del Maschio A, Luzi L: Insulin resistance, intramyocellular lipid content, and plasma adiponectin in patients with type 1 diabetes. Am J Physiol Endocrinol Metab 2003, 285:E1174-E1181.

16. Libman IM, Pietropaolo M, Arslania SA, LaPorte RE, Becker DJ: Changing prevalence of overweight children and adolescents at onset of insulintreated diabetes. Diabetes Care 2003, 26:2871-2875.

17. Purnell JQ, Dev RK, Steffes MW, Cleary PA, Palmer JP, Hirsch IB, Hokanson JE, Brunzell JD: Relationship of family history of type 2 diabetes, hypoglycemia, and auto antibodies to weight gain and lipids with intensive and conventional therapy in the Diabetes Control and Complications Trial. Diabetes 2003, 52:2623-2629.

18. Stern SE, Williams K, Ferrannini E, DeFronzo RA, Bogardus C, Stern MP: Identification of individuals with insulin resistance using routine clinical measurements. Diabetes 2005, 54:333-339.

19. Wajchenberg BL, Rassi N, Feitosa ACR, Lerário AC, Betti RTB: Doença cardiovascular no diabetes melito tipo 1. Arq Bras Endrocrinol Metab 2008, 52:387-397.

20. Krolewski AS, Kosinski EJ, Warram JH, Leland OS, Busik EJ, Asmal AC, Rand LI, Christlieb AR, Bradley RF, Kahn CR: Magnitude and determinants of coronary artery disease in juvenile-onset, insulin dependent diabetes mellitus. Am J Cardio/ 1987, 59:750-755.

21. Laing SP, Swerdlow AJ, Slater SD, Burden AC, Morris A, Waugh NR, Gatling W, Bingley PJ, Patterson CC: Mortality from heart disease in a cohort of 23,000 patients with insulin-treated diabetes. Diabetologia 2003, 46:760-765

22. DeFronzo RA, Tobin JD, Andres R: Glucose clamp technique: a method for quantifying insulin secretion and resistance. Am J Physiol 1979, 237:E214-E222.

23. Williams KV, Erbey JR, Becker D, Arslanian S, Orchard TJ: Can clinical factors estimate insulin resistance in type 1 diabetes? Diabetes 2000, 49:626-632.

24. Shay CM: Insulin Resistance in Type 1 Diabetes: Determinants and Clinical Consequences (Dissertation). Pittsburgh, PA: University of Pittsburgh, Graduate School of Public Health; 2009.

25. Szadkowska A, Pietrzak I, Mianowska B, Bodalsa-Lipinska J, Keenan HA, Toporowska-Kowalska E, Mlynarski W, Bodalski J: Insulin sensitivity in type 1 diabetic children and adolescents. Diabet Med 2008, 25:282-288.

26. Dabelea D, D'Agostino JRB, Mason CC, West N, Hamman RF, Mayer-Davis EJ, Maahs D, Klingensmith G, Knowler WC, Nadeau K: Development, validation and use of an insulin sensitivity score in youths with diabetes: the search for diabetes in youth study. Diabetologia 2011, 54:78-86

27. American Diabetes Association: Standards of medical care in diabetes-2012 Diabetes Care 2012, 35:S11-S63.

28. Jackson AS, Pollock ML: Generalized equations for predicting body density of men. Br J Nutr 1978, 40:497-504.

29. Pollock ML, Schmidt DH, Jackson AS: Measurement of cardiorespiratory fitness and body composition in the clinical setting. Compr Ther 1980, 6:12-27.

30. Thorn LM, Forsblom C, Fagerudd J, Thomas MC, Pettersson-Fernholm K, Saraheimo M, Wadén J, Rönnback M, Rosengård-Bärlund M, Björkesten CG, Taskinen MR, Groop PH, FinnDiane Study Group: Metabolic syndrome in type 1 diabetes: association with diabetic nephropathy and glycemic control (the FinnDiane study). Diabetes Care 2005, 228:2019-2024.

31. The DCCT Research Group: Weight gain associated with intensive therapy in the diabetes control and complications trial. Diabetes Care 1988 11:567-573

32. Lawrence JM, Mayer-Davis EJ, Reynolds K, Beyer J, Pettitt DJ, D'Agostino RB Jr, Marcovina SM, Imperatore G, Hamman RF: Diabetes in Hispanic American youth: Prevalence, incidence, demographics, and clinical characteristics: the SEARCH for Diabetes in Youth Study. Diabetes Care 2009, 32:S123-S132.

33. Reinehr $\mathrm{T}$, Holl RW, Roth $\mathrm{CL}$, Wiesel $\mathrm{T}$, Stachow R, Wabitsch M, Andler W, DPV-Wiss Study Group: Insulin resistance in children and adolescents with type 1 diabetes mellitus: relation to obesity. Pediatr Diabetes 2005, 6:5-12.

34. Maahs DM, Hokanson JE, Wang H, Kinney GL, Snell-Bergeon JK, East A, Bergman BC, Schauer IE, Rewers M, Eckel RH: Lipoprotein subfraction cholesterol distribution is proatherogenic in women with type 1 diabetes and insulin resistance. Diabetes 2010, 59:1771-1779.

35. Gomes MB, Cobas RA, Matheus ASM, Tannus LRM, Negrato CA, Rodacki M, Braga N, Cordeiro MM, Luescher JL, Berardo RS, Nery M, Arruda-Marques MC, Calliari LE, Noronha RM, Manna TD, Zajdenverg L, Salvodelli R, Penha FG, Foss MC, Foss-Freitas MC, Pires AC, Robles FC, Guedes M, Dib SA, Dualib P, Silva SC, Sepulvida J, Almeida HG, Sampaio E, Rea R, et al: Regional differences in clinical care among patients with type 1 diabetes in Brazil: Brazilian type 1 diabetes study group. Diabetol Metab Syndr 2012, 5:44.

36. Reaven GM: Banting lecture 1988. Role of insulin resistance in human disease. Diabetes 1988, 37:1595-1607.

37. Tielemans SMAJ, Soedamah-Muthu SS, De Neve M, Toeller M: Association of physical activity with all-cause mortality and incident and prevalent cardiovascular disease among patients with type 1 diabetes: the EURODIAB Prospective Complications Study. Diabetologia 2013, 56:82-91.

38. Nathan DM, Cleary PA, Backlund JY, Genuth SM, Lachin JM, Orchard TJ, Raskin P, Zinman B: Diabetes Control and Complications Trial/Epidemiology of Diabetes Interventions and Complications (DCCT/EDIC) Study Research Group. Intensive diabetes treatment and cardiovascular disease in patients with type 1 diabetes. N Engl J Med 2005, 353:2643-2653.

39. Williams KV, Erbey JR, Becker D, Orchard TJ: Improved glycemic control reduces the impact of weight gain on cardiovascular risk factors in type 1 diabetes. The Epidemiology of Diabetes Complications Study. Diabetes Care 1999, 22:1084-1091.

40. Vella S, Buetow L, Royle P, Livingstone S, Colhoun HM, Petrie JR: The use of metformin in type 1 diabetes: a systematic review of efficacy. Diabetologia 2010, 53:809-820. 
41. Reis JS, Bosco AA, Veloso CA, Mattos RT, Purish S, Nogueira-Machado JA, Bosco AA: Oxidizing and reducing responses in type 1 diabetic patients determined up to 5 years after the clinical onset of the disease. Acta Diabetol 2008, 45:221-224.

42. Geloneze B, Tambascia MA: Laboratorial evaluation and diagnosis of insulin resistance. Ara Bras Endocrinol Metab 2006, 50:208-215.

doi:10.1186/1758-5996-6-13

Cite this article as: Teixeira et al:: Insulin resistance and associated factors in patients with Type 1 Diabetes. Diabetology \& Metabolic Syndrome 2014 6:131.

\section{Submit your next manuscript to BioMed Central and take full advantage of:}

- Convenient online submission

- Thorough peer review

- No space constraints or color figure charges

- Immediate publication on acceptance

- Inclusion in PubMed, CAS, Scopus and Google Scholar

- Research which is freely available for redistribution 